\title{
Methicillin-resistant Staphylococcus pseudintermedius among dogs in the description of novel SCCmec variants
}

\author{
Birgitta Duim $^{\mathrm{a}, *}$, Koen M.H.W. Verstappen ${ }^{\mathrm{a}}$, Ruwani S. Kalupahana ${ }^{\mathrm{b}}$, Lakmali Ranathunga ${ }^{\mathrm{b}}$, \\ Ad C. Fluit ${ }^{\mathrm{c}}$, Jaap A. Wagenaar ${ }^{\mathrm{a}, \mathrm{d}}$ \\ a Department of Infectious Diseases and Immunology, Faculty of Veterinary Medicine, Utrecht University, Utrecht, The Netherlands \\ ${ }^{\mathrm{b}}$ Department of Veterinary Public Health and Pharmacology, Faculty of Veterinary Medicine and Animal Science, University of Peradeniya, Sri Lanka \\ ${ }^{\mathrm{c}}$ Department of Medical Microbiology, University Medical Centre Utrecht, Utrecht, The Netherlands \\ d Wageningen Bioveterinary Research, Lelystad, The Netherlands
}

\section{A R T I C L E I N F O}

\section{Keywords:}

S. pseudintermedius

SCCmec variants

ISCC Cec $_{57395}$

Sri Lanka

\begin{abstract}
A B S T R A C T
The presence and genetic characteristics of methicillin-resistant Staphylococcus pseudintermedius (MRSP) in Sri Lanka was investigated to add additional insight into global spread, emergence and evolution of MRSP. A total of 234 samples from dogs visiting veterinary clinics were cultured for staphylococci and the genomes of the MRSP isolates were sequenced, to identify resistance genes, the multilocus sequence types (MLST) and spa types. From a questionnaire the history of antimicrobial treatment and patient information was obtained.

S. pseudintermedius was isolated from 116/229 samples, eight of these were MRSP. Six MRSP CC45 isolates

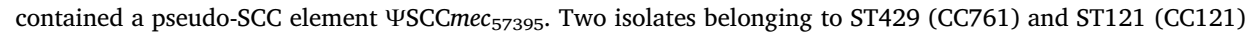
contained novel variants of the SCCmec Type V(T) element. The elements were designated SCCmecV(T) $)_{\mathrm{SL} / 066}$, that carried additional transposon-related genes, and $\operatorname{SCCmecV}(\mathrm{T})_{\mathrm{SL} / 154}$ that carried a type III restrictionmodification system, a type $7 \mathrm{ccr}$ gene complex, and a cadA coding sequence. Thirty-seven percent of the dogs received antimicrobial treatment at the time of sampling of which four dogs were MRSP-positive. The proportion of MRSP among $S$. pseudintermedius is low compared to other countries, despite the fact that in Sri Lanka antimicrobials for treatment of dogs are available over the counter. Important is the finding of novel type $\mathrm{V}(\mathrm{T})$ SCCmec elements, which further underlines the high recombination frequency of SCC elements. The ISCCmec $_{57395}$ was found in isolates of CC45, which is the only sequence type of MRSP known to contain this pseudo-cassette.
\end{abstract}

\section{Introduction}

Staphylococcus pseudintermedius is a major opportunistic pathogen in cats and dogs. It causes skin and soft tissue infections, otitis externa, and wound infections after surgery (van Duijkeren et al., 2011). S. pseudintermedius can be transmitted to humans, but $S$. pseudintermedius in humans might be misdiagnosed as Staphylococcus aureus because they share key biochemical characteristics such as the ability to produce coagulase (Börjesson et al., 2015). As with $S$. aureus, S. pseudintermedius can contain a mobile element called Staphylococcal Cassette Chromosome mec (SCCmec). A typical SCCmec cassette contains a recombinase gene complex (ccr) and a mec gene complex, which contains the mecA gene. Additional genes with a variety of functions can also be present, such as transposons, IS-elements, restriction-modification systems, and resistance genes against metals (Ito et al., 2009). The mecA gene encodes for an alternative penicillin-binding protein (PBP). This alternative protein has a lower affinity for $\beta$-lactam antimicrobials than the regular PBP. S. pseudintermedius strains that contain the mecA gene are called methicillin-resistant $S$. pseudintermedius (MRSP). Strains of MRSP are often resistant against multiple classes of antimicrobials (MDR), which can make it a challenge to treat MRSP infections (Weese and van Duijkeren, 2010).

MRSP has been found all over the world, but genetic types differ between geographical locations. For example, multilocus sequence type (MLST) ST71 is the predominant type found in Northern Europe, while ST68 is predominant in Northern America (Perreten et al., 2010) and ST45 in Asia (Perreten et al., 2013). MRSP has been reported from China (Feng et al., 2012), Thailand (Perreten et al., 2013), South Korea (Yoon et al., 2010), Indonesia (Soedarmanto et al., 2011), and India (Chitra et al., 2015). However, it is unknown if MRSP is also present in

\footnotetext{
* Corresponding author.

E-mail addresses: b.duim@uu.nl (B. Duim), kmhwverstappen@gmail.com (K.M.H.W. Verstappen), ruwanikalupahana@yahoo.com (R.S. Kalupahana), lakmalirana@gmail.com (L. Ranathunga), a.c.fluit@umcutrecht.nl (A.C. Fluit), j.wagenaar@uu.nl (J.A. Wagenaar).
} 
Sri Lanka.

In Sri Lanka, there is no surveillance for antimicrobial resistance among bacteria or antimicrobial usage and professional oversight for antimicrobial use is often lacking in humans and animals. The aim of this study was to obtain information about the molecular epidemiology of MRSP associated with carriage and infections in dogs in Sri Lanka.

\section{Materials and methods}

\subsection{Sampling}

Samples were obtained in March 2014 from dogs attending veterinary clinics (primary healthcare clinics, private veterinary clinics, veterinary hospital, veterinary teaching hospital) in regions of Peradeniya and Colombo in Sri Lanka. Samples were obtained from either skin lesions (if present), the groin, or the ear using a dry swab (one swab per dog). Approval for this study was obtained from the Ethics Committee of the Faculty of Veterinary Medicine and Animal Science at the University of Peradeniya, as discussed in their meeting on 28th February 2014. For every dog a short questionnaire was filled in by the veterinarian and the dog owner. The following parameters were recorded: name of the dog, age, sex, reason for visiting the veterinary clinic, if the dog was on antimicrobial treatment at the time of sampling, and antimicrobials used for treatment. If the dog did not receive antimicrobial treatment at the time of sampling it was asked when the last antimicrobial treatment was applied.

\subsection{Sample analysis}

As described before, (Laarhoven et al., 2011) samples were cultured overnight $(\mathrm{O} / \mathrm{N})$ in Mueller Hinton Broth (MH; Oxoid, the Netherlands) with $6.5 \% \mathrm{NaCl}$ on the day of sampling and subcultured on Colombia agar with $5 \%$ sheep blood (BA) to isolate all $S$. pseudintermedius. Besides plating on BA, the $\mathrm{MH}$ enrichment was also subcultured in Phenol Red Mannitol broth (PMB; Oxoid) with aztreonam $(75 \mathrm{mg} / \mathrm{L})$ and ceftizoxime $(5 \mathrm{mg} / \mathrm{L})$, both from Sigma Aldrich, the Netherlands to select for MRSP. After $\mathrm{O} / \mathrm{N}$ incubation, $\mathrm{PMB}$ was also subcultured on BA. Colonies on BA (after MH and after PMB) that were suspected to be $S$. pseudintermedius were subcultured on fresh BA and tested by Gram stain, mannitol fermentation and coagulase tube test and stored at $-80{ }^{\circ} \mathrm{C}$ in nutrient broth (Oxoid) with $15 \%$ glycerol. Suspected isolates were shipped to the Netherlands (frozen on dry ice) and confirmed by MALDI-TOF MS (Bruker, Germany) and mecA PCR (Francois et al., 2003).

\subsection{Whole genome sequencing}

All isolates that were confirmed as MRSP were genotyped using whole genome sequencing (WGS). DNA was isolated with the Ultra
Clean Microbial DNA isolation kit (Mo-Bio, Carlsbad CA, U.S.A.) with additional external lysis with achromopeptidase (Sigma Aldrich). MiSeq sequencing (Illuminia, San Diego, California, USA) was performed at the Utrecht Sequencing Facility (UMC Utrecht, the Hubrecht Institute and Utrecht University, the Netherlands). Reads were assembled into a scaffold genome consisting of contigs using SPAdes v3.1.1 (Bankevich et al., 2012). Genome sequences were deposited in GenBank under accession numbers listed in Table 2. Allele sequences for MLST were extracted using BLASTN and the STs were identified as described previously (Solyman et al., 2013). Clonal Complexes were assigned using the pubMLST Burst analysis (https://pubmlst.org). The sequences encoding protein A were also extracted using BLASTN and used for spatyping (Moodley et al., 2009). Acquired resistance genes were identified using the ResFinder and CARD databases (accessed on August 2017) (Jia et al., 2017; Zankari et al., 2012) The single nucleotide polymorphisms (SNPs) in the core genome sequences were compared using parsnp v1.2 (19) and visualised using TreeViewX. The genome sequence of strain ED99 (GenBank accession CP002478) was used as a reference.

\subsection{Identification of SCCmec elements in MRSP}

Contigs associated with SCCmec were extracted from the genome sequence and annotated using Prokka (Seemann, 2014). SCCmec-types were assigned based on the presence of elements as described in the guidelines (Ito et al., 2009), and aligned with the reference SCCmec sequences using ACT v13.0.0. Only for isolate SL/154 the reads belonging to the SCCmec region could not be automatically combined into one contig that spanned the entire SCCmec element. Therefore, the contig order was confirmed by primer walking and Sanger sequencing from the mecA gene to maoC. Sanger sequencing reads were aligned using BioNumerics v7.5 and had a read coverage between 4 and $8 x$ using different primer sets. Comparative analysis of the final SCCmec assemblies was performed using Geneious vs. 9.0.2 (Biomatters Ltd., NZ). A figure of SCCmec sequence comparisons using SCCmec type V(T) (GenBank accession ERR175868) as reference, was produced using EasyFig v2.2.2 (Sullivan et al., 2011).

\section{Results}

A total of 234 dogs were sampled during a study in the regions of Peradeniya $(n=217)$ and Colombo $(n=17)$ in 2014. Five of these dogs were excluded due to lack of information. From dogs of 9 veterinary hospitals a total of 229 samples were obtained that were divided in three groups: 39 dogs included for vaccination were considered as healthy dogs, 190 dogs with clinical infections of which 16 could be associated with $S$. pseudintermedius infections, based on their clinical manifestations (Table 1). The mean and median age of the dogs were 38.8 and 24.0 months, respectively (ranging from 2 weeks to 14 years).

Table 2

Genotypic characteristics of the MRSP isolates.

\begin{tabular}{|c|c|c|c|c|c|c|c|c|c|c|c|c|c|c|c|}
\hline \multirow{2}{*}{\multicolumn{2}{|c|}{ Strain numbers }} & \multirow{3}{*}{$\begin{array}{l}\text { MLST } \\
\text { ST } 429\end{array}$} & \multirow{3}{*}{$\begin{array}{l}\text { spa type } \\
\text { t75 }\end{array}$} & \multirow{3}{*}{ 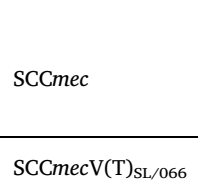 } & \multirow{3}{*}{$\begin{array}{l}\text { GenBank Accession } \\
\text { No. } \\
\text { MQMO00000000 }\end{array}$} & \multicolumn{10}{|c|}{ Resistance genes } \\
\hline & & & & & & \multirow{2}{*}{$\begin{array}{l}\text { mecA } \\
+\end{array}$} & \multirow{2}{*}{$\begin{array}{l}\text { blaZ } \\
+\end{array}$} & \multirow{2}{*}{$\begin{array}{l}\operatorname{aac}\left(6^{\prime}\right)-I e- \\
\operatorname{aph}\left(2^{\prime \prime}\right)-I a \\
+\end{array}$} & \multirow{2}{*}{$\begin{array}{l}\text { aph } \\
\left(3^{\prime}\right)-I I I\end{array}$} & \multirow{2}{*}{$\begin{array}{l}\text { ant } \\
(6)-I a\end{array}$} & \multirow{2}{*}{$\begin{array}{l}\text { sat-4 } \\
+\end{array}$} & \multirow{2}{*}{$\begin{array}{l}\operatorname{erm}(B) \\
-\end{array}$} & \multirow{2}{*}{$\begin{array}{l}d f r G \\
+\end{array}$} & \multirow{2}{*}{$\begin{array}{l}\operatorname{tet}(M) \\
+\end{array}$} & \multirow{2}{*}{$\begin{array}{l}\operatorname{cat}(p C 221) \\
-\end{array}$} \\
\hline $14 S 02752-1$ & SL/066 & & & & & & & & & & & & & & \\
\hline $14 S 02760-1$ & SL/076 & ST 45 & t09 & $\Psi_{\text {SCCmec }} \mathrm{C}_{57395}$ & MQMP00000000 & + & + & + & + & + & + & + & + & + & + \\
\hline $14 S 02692-1$ & SL/085 & ST 45 & t09 & $\Psi_{S C C m e c}{ }_{57395}$ & MQNB00000000 & + & + & + & + & + & + & + & + & + & + \\
\hline $14 S 02708-1$ & SL/094 & ST 45 & t09 & $\Psi_{S C C m e c} 57395$ & MQNC00000000 & + & + & + & + & + & + & + & + & + & + \\
\hline $14 S 02884-1$ & SL/114 & ST 282 & t09 & $\Psi_{S C C m e c}{ }_{57395}$ & MQND00000000 & + & + & + & + & + & + & + & + & + & + \\
\hline \multirow[t]{2}{*}{$14 \mathrm{~S} 02826-1$} & SL/152 & ST 282 & No spa & ISCCmec $_{57395}$ & MQNE00000000 & + & + & + & + & + & + & + & - & + & + \\
\hline & SL/154 & ST 121 & t06 & $\operatorname{sCCmecV(T)_{SL/154}}$ & MQNF00000000 & + & + & + & + & + & + & + & + & + & + \\
\hline $14 S 02854-1$ & SL/164 & ST 282 & $\mathrm{t} 72$ & 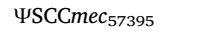 & MQNG00000000 & + & + & + & + & + & + & + & + & + & + \\
\hline
\end{tabular}

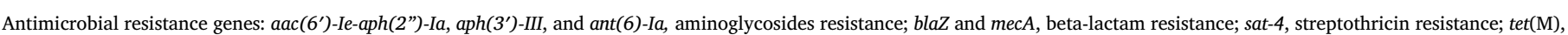
tetracycline resistance; $\operatorname{cat}(\mathrm{pC} 221)$, chloramphenicol resistance; $\mathrm{erm}(\mathrm{B})$, macrolide resistance; $d f r G$, trimethoprim resistance. 
Table 1

S. pseudintermedius strains isolated from dogs in Sri Lanka.

\begin{tabular}{|c|c|c|c|c|c|c|c|c|}
\hline \multirow{2}{*}{$\begin{array}{l}\text { veterinary hospitals }(n=9) \text { patient } \\
\text { inclusion }\end{array}$} & \multirow[t]{2}{*}{ no. samples } & \multirow[t]{2}{*}{ sources } & \multicolumn{2}{|c|}{ no. MSSP } & \multirow[t]{2}{*}{$\%$ MSSP positive } & \multirow[t]{2}{*}{ no. $\mathrm{MRSP}^{\mathrm{a}}$} & \multirow{2}{*}{$\begin{array}{l}\% \text { MRSP/ } \\
\text { MSSP }\end{array}$} & \multirow[t]{2}{*}{$\%$ MRSP } \\
\hline & & & pos & neg & & & & \\
\hline vaccination (healthy) & 39 & ear $(n=25)$, skin $(n=14)$ & 21 & 18 & 53.8 & 0 & 0 & 0 \\
\hline clinical & 174 & $\begin{array}{l}\text { ear }(n=67) \text {, skin }(n=98) \text {, skin lesions } \\
(n=9)\end{array}$ & 85 & 89 & 48.9 & 7 & 8.2 & 4.0 \\
\hline non-clinical potential MSSP/MRSP & 16 & $\begin{array}{l}\text { ear }(n=10) \text {, skin }(n=3), \text { skin lesions } \\
(n=3)\end{array}$ & 10 & 6 & 62.5 & 1 & 10.0 & 6.25 \\
\hline Total & 229 & & 116 & 113 & 50.7 & 8 & 7.6 & 3.5 \\
\hline
\end{tabular}

MSSP; methicillin-susceptible $S$. pseudintermedius, MRSP; methicillin-resistant $S$. pseudintermedius.

${ }^{\text {a }}$ The number of $S$. pseudintermedius strains that were MRSP.

All samples were processed on the day of collection and S. pseudintermedius was isolated from 116/229 (50.7\%) samples, of which 8 isolates were MRSP in $3.5 \%$ of the samples (Table 1). No MRSP was isolated from dogs that attended the hospitals for vaccination. From these dogs $53.8 \%$ carried $S$. pseudintermedius. There were 16 dogs with clinical symptoms that are often associated with $S$. pseudintermedius infections (otitis, dermatitis or pyoderma or previously $S$. pseudintermedius positive). Of these dogs 10 were positive for $S$. pseudintermedius, of which one was MRSP. This number of isolated MSSP was not significantly different from the number of MSSP isolated from healthy dogs. The total proportion of MRSP among S. pseudintermedius was $7.6 \%$.

\subsection{Genetic characteristics of MRSP isolates}

Whole genome sequencing of the eight MRSP isolates showed that six isolates belonged to CC45 with ST45 and ST282 (a single locus variant of ST45 with one nucleotide difference in the tuf gene) (Duim et al., 2016; McCarthy et al., 2015). Of these isolates, three ST45 isolates and one ST282 belonged to spa-type t09, one ST282 isolate belonged to spa-type t72, which is similar to t09 but lacks the -13-03repeats and for one ST282 isolate no spa-type could be assigned because the sequence was not present in the genome sequence (Table 2). The remaining two strains belonged to ST121 (CC121) and ST429 (CC761) with spa-types t06 and t75 respectively. Spa-type t75 is similar to t06, except for an insert with additional $-[03]_{4}-34$ - repeats. The parsnpanalysis of the core genomes corroborated the results of the MLST, as displayed in Fig. 1, the core genome of the ST45-isolates were highly similar, with the ST282-isolates (CC45) as nearest neighbours.

All isolates contained genes encoding antimicrobial resistance to multiple classes of antimicrobials. All the isolates carried aac(6')-Ie-aph (2")-Ia, aph(3')-III, and ant(6)-Ia genes encoding resistance to aminoglycosides; blaZ and mecA encoding resistance against beta-lactams; tet(M) encoding resistance against tetracyclines; and sat-4 involved in streptothricin resistance. The genes cat(pC221), encoding resistance against chloramphenicol; and erm(B), encoding resistance against macrolides, lincosamides and streptogramin B antimicrobials, were detected in all isolates except strain SL/066. The $d f r G$ gene encoding resistance to trimethoprim was detected in all isolates except in strain SL/152 (Table 2).

\subsection{Distribution of SCCmec elements and identification of novel variants}

The MRSP CC45 isolates (SL/076, SL/085, SL/094, SL/114, SL/152, and SL/164) contained the pseudo-SCCmec element ISCCmec $_{57395}$, which was previously described in MRSP isolates from Thailand and Israel (Perreten et al., 2013). This SCCmec element contains a class C1 mec gene complex (mecA gene and two IS431 elements in the same direction), cadmium, arsenic, and copper resistance genes, but no $c c r$ genes.

Isolates SL/066 and SL/154 contained novel SCCmec variants that

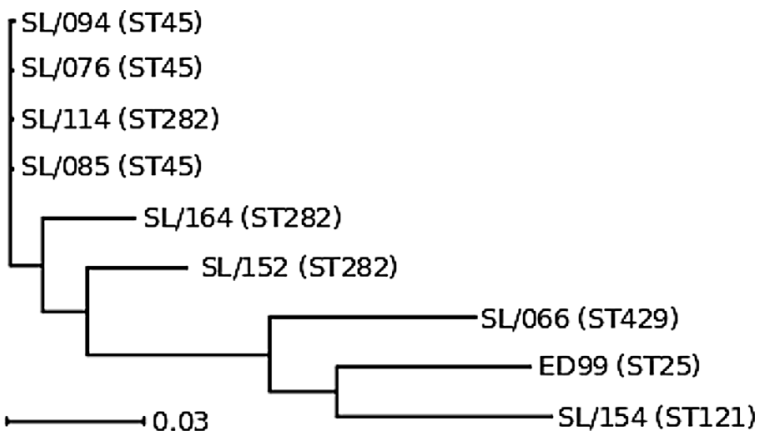

Fig. 1. Non-rooted neighbour-joining tree of the parsnp-comparison of MRSP genomes. The genome of $S$. pseudintermedius strain ED99 was added as reference. The accession numbers of the genomes are listed in Table 1.

shared the highest homology with the sequence of the SCCmec Type V (T) element described for MRSP strain 23929 from Ireland (McCarthy et al., 2015). This Type V(T) element of 56,986 bp carried a type II restriction-modification system, CRISPR-cas complex, two ccrC8 genes, and a class $\mathrm{C} 2$ mec gene complex. The structures of the identified SCCmec elements were highly similar to this element as shown in Fig. 2. The nucleotide sequences at the left and right chromosomal junctions of all three elements were similar and were demarcated by direct repeats. At the left the integration site sequence of the SCCmec element was downstream of $\operatorname{orf} X$, and at the right end the elements were demarcated by direct repeats upstream of CRISPR-cas sequences and two genes encoding hypothetical proteins (Fig. 2). The SCCmec element of isolate SL/154 was 57,051 bp in size and contained directly downstream of the OrfX integration site, a type III restriction modification system, a $c c r$ gene complex consisting of $c c r A 1$ and $c c r B 6$ ( $c c r$ gene complex 7) and carried a cadA gene. Although the right end of the sequence carrying the CRISPR-cas region was highly similar to the SCCmec type V(T) element, a reverse transcriptase gene was inserted in the maoC gene, located 1618 bp upstream of mecA (Fig. 2). This SCCmec type was designated SCCmec Type $\mathrm{V}(\mathrm{T})_{\mathrm{SL} / 154}$. The SCCmec element of strain SL/066 contained between orf $X$ and the mecA gene open reading frames of hypothetical proteins and coding sequences of transposon-related genes of which the sequence had $85 \%$ similarity to the insertion sequence, ISSau5, which has been identified in MRSA252 (Holden et al., 2004) (Fig. 2). This sequence in the element of strain SL/066 also showed $100 \%$ similarity with an insertion sequence in the genome of an $S$. pseudintermedius isolate from a dog in Tennessee in the United States, but this sequence was not annotated and was not flanked by genes related to an SCCmec element (GenBank accession CP015626.1). The right end of the SCCmec element of strain SL/066 was, just as the element of strain SL/154, highly similar to the sequence of the SCCmec V (T) element. This cassette of MRSP strain SL/066 was designated SCCmec V(T) $)_{\mathrm{SL} / 066}$. 


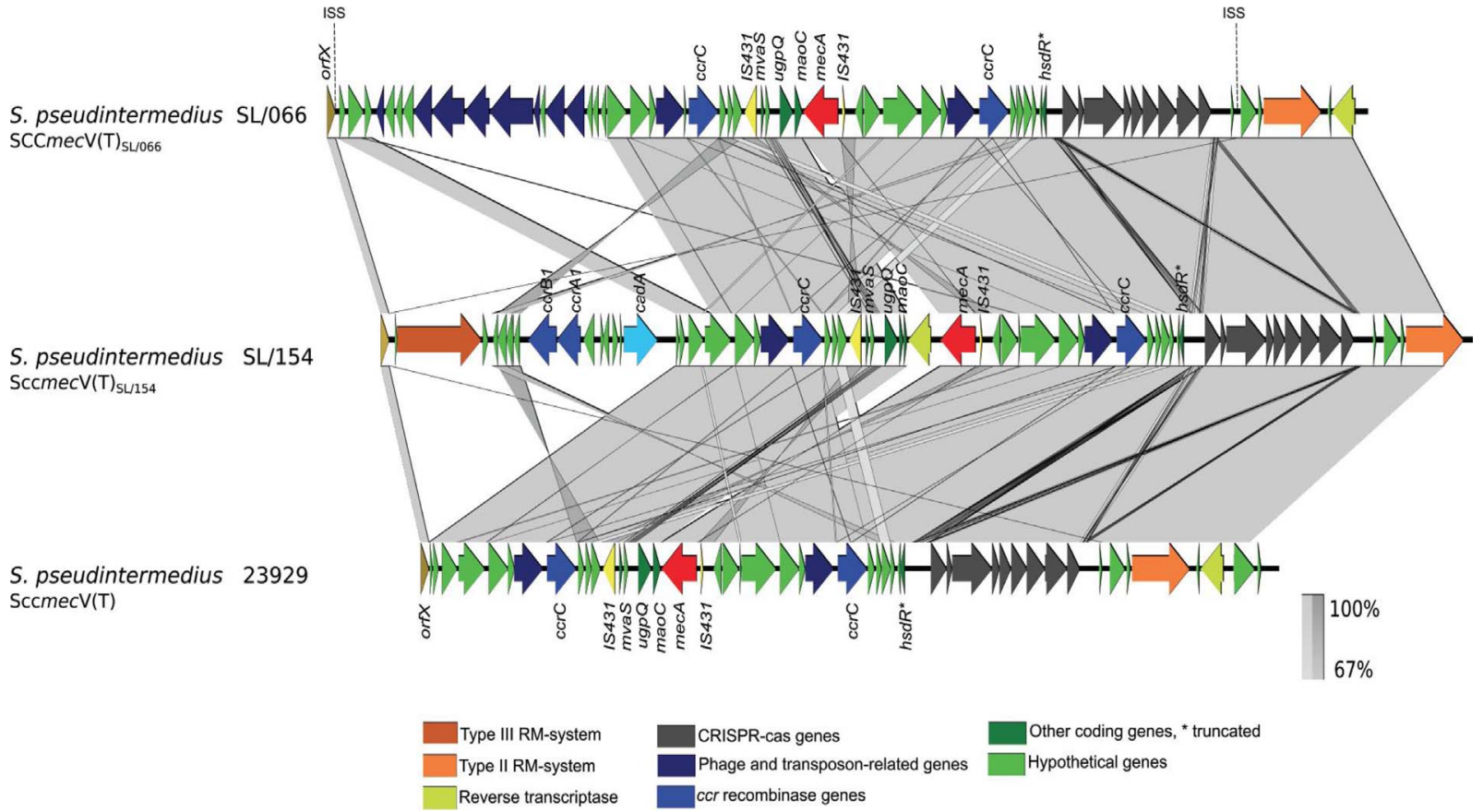

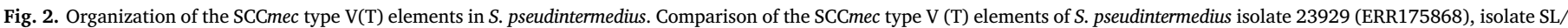

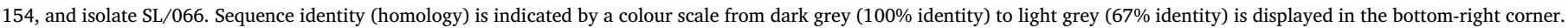

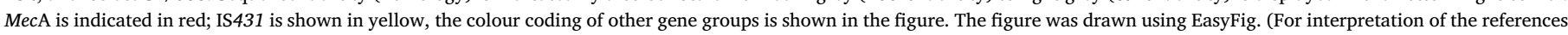
to colour in this figure legend, the reader is referred to the web version of this article.)

\subsection{Antimicrobial use in dogs}

At the time of sampling $82 / 229(35.8 \%)$ dogs received antimicrobial treatment, 156/229 (62\%) received no treatment at the time of sampling. Most dogs received a combination of ceftriaxone and metronidazole at the time of sampling (26/82) (Table 3).

Of the 156 dogs that received no antimicrobial treatment at the day of sampling, 22 received their last treatment more than a year prior to sampling, 14 were treated between six months and a year before sampling, 12 were treated in the six months prior to sampling, one dog was never treated and of 107 dogs it was unknown if they received antimicrobial treatment. However, the data on treatment were insufficient to explore the association between the presence of MRSP and the use of antimicrobials.

\section{Discussion}

Identification of MRSP in dogs in Sri Lanka and the genetic

Table 3

Antimicrobial use at the time of sampling and previous.

\begin{tabular}{|c|c|c|c|c|}
\hline & Dogs & No. MSSP positive & No. MSSP negative & No. MRSP positive \\
\hline Antimicrobial combination & No. Treated & carriage/ clinical & carriage/ clinical & carriage/ clinical \\
\hline amoxicillin & 4 & $2 / 0$ & $2 / 0$ & - \\
\hline amoxicillin + clavulanic acid & 5 & $3 / 0$ & $2 / 0$ & - \\
\hline amoxicillin and enrofloxacin (topical) & 1 & $0 / 1$ & - & $0 / 1$ \\
\hline ampicillin & 1 & - & $1 / 0$ & - \\
\hline cefrimenzole & 4 & $1 / 0$ & $0 / 3$ & - \\
\hline ceftriaxone & 10 & $3 / 0$ & $2 / 5$ & - \\
\hline ceftriaxone and metronidazole & 26 & $1 / 13$ & $0 / 12$ & $0 / 1$ \\
\hline ceftriaxone and oxytetracycline & 3 & - & $3 / 0$ & - \\
\hline cephalexin & 3 & - & $3 / 0$ & - \\
\hline ciprofloxacin & 1 & $1 / 0$ & - & - \\
\hline clindamycin, metronidazole and doxycycline & 1 & - & $1 / 0$ & - \\
\hline cloxacillin & 2 & $0 / 2$ & - & $0 / 1$ \\
\hline cotrimoxazole & 2 & $1 / 0$ & $1 / 0$ & \\
\hline doxycycline & 2 & $1 / 1$ & - & $0 / 1$ \\
\hline doxycycline and cefuroxime & 1 & - & $1 / 0$ & - \\
\hline metronidazole & 3 & - & $3 / 0$ & - \\
\hline metronidazole and trimethoprim-sulfamethoxazole & 1 & $1 / 0$ & - & - \\
\hline oxytetracycline & 3 & $1 / 0$ & $2 / 0$ & - \\
\hline No antimicrobial treatment at the time of sampling & 156 & $6 / 78$ & $0 / 72$ & $0 / 4$ \\
\hline Previous treatment $>1$ year & 22 & & & \\
\hline Previous treatment $>6$ months & 14 & & & \\
\hline Previous treatment $<6$ months & 12 & & & \\
\hline No treatment & 1 & & & \\
\hline Unknown previous treatments & 107 & & & \\
\hline
\end{tabular}


characteristics of isolates supports the understanding of the spread of successful resistant clones. In this study six of the eight identified MRSP isolates belonged to CC45. This clonal complex is a successful clone in Asia, of which strains have been shown to carry the pseudo-SCCmec element ISCCmec $_{57395}$ (Perreten et al., 2013). The CC45 isolates from Sri Lanka were all carrying this pseudo-SCCmec element, that could suggest that the isolates carrying this element arose from a common ancestor, and may have been introduced in Sri Lanka from other countries. From the clonal distribution of CC45 YSCCmec $_{57395}$ it seems unlikely that strains evolved independently in Sri Lanka through horizontal transfer and recombination. Introduction of strains from other countries seems plausible and is in accordance with the hypothesis described by Perreten et al. Analysis of SNPs in the core genome showed that four CC45 isolates contain identical polymorphisms, and that two CC45 isolates contained more SNPs that diverged them into a different sequence type (ST282) with divergent spa-types (t72 and no spa-type) (Fig. 1). Strains without spa gene have been described before in South China (Feng et al., 2012), the Netherlands (Laarhoven et al., 2011), Israel and Thailand (Perreten et al., 2013). The two dogs from which these isolates were recovered were from different towns, so it is unlikely that they both have a recent common source for this strain, and is it likely that these isolates diverged from ST45 after the integration of YSCCmec 57395 . Unfortunately are genome sequences of CC45 S. pseudintermedius strains from other countries not available for accurate estimation of the evolution and dissemination of MRSP CC45.

Characterisation of the SCCmec elements showed two novel variants of the SCCmec V(T) element. This element was originally described in community-associated methicillin-resistant $S$. aureus (CA-MRSA) from Taiwan (now designated SCCmec type VII in S. aureus) and is characterized by a class C2 mec gene complex flanked with two copies of IS341 elements and a ccrC gene complex (Boyle-Vavra et al., 2005; Takano et al., 2008). In S. pseudintermedius the SCCmec type V(T) element has been identified in isolates from dogs in the USA and Ireland (Black et al., 2009; McCarthy et al., 2015). In contrast to the SCCmec type $\mathrm{V}(\mathrm{T})$ and type $\mathrm{V}(5 \mathrm{C} 2 \& 5)$ in MRSA, that often carry other resistance genes and genes related to the detoxification of heavy metals, the SCCmec type V(T) in MRSP carries a CRISPR-cas region (Li et al., 2011; McCarthy et al., 2015). At the time of writing only five SCCmec elements were identified in MRSP, but variants unique to this species have been identified (Chanchaithong et al., 2016). Isolate SL/154 contained a SCCmec V(T) related element with an additional sequence that resembles an SCC element containing a ccr gene complex, but without a mec gene complex (Fig. 2). This may suggest the integration of an SCC element within another SCC element, which has been described before in $S$. aureus (Jansen et al., 2006). This additional sequence in the element of isolate SL/154 contained a type $7 \mathrm{ccr}$ gene complex, which has been described in SCCmec type X (Li et al., 2011). Although the type X element also contains a cadmium-resistance gene downstream of the $\mathrm{ccr}$ gene complex, this is a cadD resistance gene, while the cadmium resistance gene in isolate SL/154 is a cadA gene (Crupper et al., 1999; Nucifora et al., 1989). Upstream of the ccr gene complex, the SCCmec Type $\mathrm{X}$ has the mec gene complex and arsenic resistance genes, which are both not present in the inserted sequence in SL/154. This suggests that the insert in isolate SL/154 is not an insert of a mecA-lacking SCCmec type X, but rather suggest the integration of a combined sequence, or a yet unknown cassette variant. It would require finding additional variants similar to this SCC to elucidate the origin of this recombinant sequence.

All the MRSP isolates from dogs in Sri Lanka carried multiple resistance genes. The beta-lactam resistance gene mecA, the aminoglycoside resistance genes aac(6')-Ie-aph(2")-Ia, aph(3')-II and ant(6)-Ia, the streptothricin resistance gene sat-4, and the tetracycline resistance gene tet(M) were present in all strains. This is a common resistance gene profile in CC45 MRSP isolates in Thailand and China (Chanchaithong et al., 2014; Feng et al., 2012; Perreten et al., 2013), but is also common in Europe and North America, in CC45 strains and in strains belonging to other STs (Duim et al., 2016; Perreten et al., 2010). In addition, 7 strains in Sri Lanka carried the trimethoprim resistance gene $d f r G$, the macrolide resistance gene $\operatorname{erm}(B)$, or the chloramphenicol resistance gene cat(pC221). These resistance genes have also been detected in strains from Thailand and China (Chanchaithong et al., 2014; Feng et al., 2012; Perreten et al., 2013). These studies included isolates from healthy and diseased dogs similar as the studied Sri Lankan isolates, but our study showed that most of the dogs that were considered healthy, carried MSSP but no MRSP. The proportion of MRSP among S. pseudintermedius isolates was $7.6 \%$, which is similar to the long-term proportion of around $7 \%$ that has been identified in the Netherlands in recent years (Duim et al., 2016). However, in Finland a proportion of 11.5\% was found in screening dogs in 2015 (Grönthal et al., 2017), and in a study among dogs visiting a Japanese Veterinary Clinic an MRSP prevalence of $30 \%$ was found (Sasaki et al., 2007). As in our study only one swab per dog was analysed, is it possible that the identified MRSP proportion in Sri Lanka may be underestimated. Furthermore, may the differences in MRSP proportion reflect geographical differences, but may also result from differences in the study population, as MRSP is recognized as nosocomial pathogen in veterinary clinics. It anyhow underlines that multidrug-resistant MRSP strains disseminate worldwide.

Of the dogs $35.8 \%$ received antimicrobial treatment at the time of sampling. Many dogs were treated with ceftriaxone, a drug that should be administered parenterally for several days. It most likely was used for treatment of an outbreak with diarrhoea (personnel communication), that might have been the reason for visiting the clinic on the day of sampling. The other antimicrobials that were frequently used was a combination of ceftriaxone and metronidazole. In a study in the United Kingdom $45.1 \%$ of 34,928 dogs visiting 11 veterinary clinics left with a prescription for antimicrobials, but no data was available on how many animals were already on antimicrobial treatment before they attended the clinic (Mateus et al., 2011). Documentation about antimicrobial usage and general figures on antimicrobial resistance in companion animals in Sri Lanka are unfortunately not available, but our study showed that use of antimicrobials for treatment of dogs in Sri Lanka was high. In human medicine there is concern about the high level of antimicrobial resistance in Sri Lanka (Chandrasiri et al., 2013) and given the high use of antimicrobials for treatment of dogs, is monitoring of resistances important.

In conclusion, MRSP is present in dogs in Sri Lanka. We observed clonal dissemination of isolates belonging to CC45 carrying the pseudoSCCmec element ISCCmec $_{57395}$, and identified novel variants of the SCCmec $\mathrm{V}(\mathrm{T})$ elements in two strains with unrelated STs. This provides further evidence for the ongoing diversification of MRSP by recombination in the SCCmec element.

\section{Funding}

This work was partially funded by the National Research Council, Sri Lanka (grant no. 14-105).

\section{Transparency declarations}

None to declare.

\section{Acknowledgements}

We thank all veterinary surgeons from the participating veterinary clinics for taking the samples and filling in the questionnaires together with the participants. We are grateful Professor Preeni Abeynayake for making outstanding logistic arrangements during this project. We thank Dr. Aldert Zomer (Utrecht University) for his excellent advice on the sequence analysis. 


\section{References}

Bankevich, A., Nurk, S., Antipov, D., Gurevich, A.A., Dvorkin, M., Kulikov, A.S., Lesin, V.M., Nikolenko, S.I., Pham, S., Prjibelski, A.D., Pyshkin, A.V., Sirotkin, A.V., Vyahhi, N., Tesler, G., Alekseyev, M.A., Pevzner, P.A., 2012. SPAdes: a new genome assembly algorithm and its applications to single-cell sequencing. J. Comput. Biol. 19, 455-477. http://dx.doi.org/10.1089/cmb.2012.0021.

Black, C.C., Solyman, S.M., Eberlein, L.C., Bemis, D.A., Woron, A.M., Kania, S.A., 2009 Identification of a predominant multilocus sequence type, pulsed-field gel electrophoresis cluster, and novel staphylococcal chromosomal cassette in clinical isolates of mecA-containing, methicillin-resistant Staphylococcus pseudintermedius. Vet. Microbiol. 139, 333-338. http://dx.doi.org/10.1016/j.vetmic.2009.06.029.

Börjesson, S., Gómez-Sanz, E., Ekström, K., Torres, C., Grönlund, U., 2015. Staphylococcus pseudintermedius can be misdiagnosed as Staphylococcus aureus in humans with dog bite wounds. Eur. J. Clin. Microbiol. Infect. Dis. 34, 839-844. http://dx.doi.org/10. 1007/s10096-014-2300-y.

Boyle-Vavra, S., Ereshefsky, B., Wang, C.-C., Daum, R.S., 2005. Successful multiresistant community-associated methicillin-resistant Staphylococcus aureus lineage from Taipei, Taiwan, that carries either the novel Staphylococcal chromosome cassette mec SCCmec type V(T) or SCCmec type IV. J. Clin. Microbiol. 43, 4719-4730. http://dx. doi.org/10.1128/JCM.43.9.4719-4730.2005.

Chanchaithong, P., Perreten, V., Schwendener, S., Tribuddharat, C., Chongthaleong, A., Niyomtham, W., Prapasarakul, N., 2014. Strain typing and antimicrobial susceptibility of methicillin-resistant coagulase-positive staphylococcal species in dogs and people associated with dogs in Thailand. J. Appl. Microbiol. 117, 572-586. http://dx. doi.org/10.1111/jam.12545.

Chanchaithong, P., Prapasarakul, N., Perreten, V., Schwendener, S., 2016. Characterization of a novel composite Staphylococcal cassette chromosome mec in methicillin-resistant Staphylococcus pseudintermedius from Thailand. Antimicrob. Agents Chemother. 60, 1153-1157. http://dx.doi.org/10.1128/AAC.02268-15.

Chandrasiri, P., Elwitigala, J., Nanayakkara, G., Chandrasiri, S., Patabendige, G., Karunanayaka, L., Perera, J., Somaratne, P., Jayathilleke, K., 2013. A multi centre laboratory study of gram-negative bacterial blood stream infections in Sri Lanka. Ceylon Med. J. 58. http://dx.doi.org/10.4038/cmj.v58i2.5680.

Chitra, M.A., Jayanthy, C., Nagarajan, B., 2015. Detection and sequence analysis of accessory gene regulator genes of Staphylococcus pseudintermedius isolates. Vet. World 8, 902-907. http://dx.doi.org/10.14202/vetworld.2015.902-907.

Crupper, S.S., Worrell, V., Stewart, G.C., Iandolo, J.J., 1999. Cloning and expression of cadD, a new cadmium resistance gene of Staphylococcus aureus. J. Bacteriol. 181, 4071-4075

Duim, B., Verstappen, K.M., Broens, E.M., Laarhoven, L.M., Van Duijkeren, E., Hordijk, J., De Heus, P., Spaninks, M., Timmerman, A.J., Wagenaar, J.A., 2016. Changes in the population of methicillin-resistant Staphylococcus pseudintermedius and dissemination of antimicrobial-resistant phenotypes in the Netherlands. J. Clin. Microbiol. 54 (2), 283-288. http://dx.doi.org/10.1128/JCM.01288-15.

Feng, Y., Tian, W., Lin, D., Luo, Q., Zhou, Y., Yang, T., Deng, Y., Liu, Y.-H., Liu, J.-H., 2012. Prevalence and characterization of methicillin-resistant Staphylococcus pseudintermedius in pets from South China. Vet. Microbiol. 160, 517-524. http://dx.doi. org/10.1016/j.vetmic.2012.06.015.

Francois, P., Pittet, D., Bento, M., Pepey, B., Vaudaux, P., Lew, D., Schrenzel, J., 2003. Rapid detection of methicillin-resistant Staphylococcus aureus directly from sterile or nonsterile clinical samples by a new molecular assay. J. Clin. Microbiol. 41, 254-260.

Grönthal, T., Eklund, M., Thomson, K., Piiparinen, H., Sironen, T., Rantala, M., 2017. Antimicrobial resistance in Staphylococcus pseudintermedius and the molecular epidemiology of methicillin-resistant $S$. pseudintermedius in small animals in Finland. J. Antimicrob. Chemother. 72 (4), 1021-1030. http://dx.doi.org/10.1093/jac/dkw559.

Holden, M.T.G., Feil, E.J., Lindsay, J.A., Peacock, S.J., Day, N.P.J., Enright, M.C., Foster, T.J., Moore, C.E., Hurst, L., Atkin, R., Barron, A., Bason, N., Bentley, S.D., Chillingworth, C., Chillingworth, T., Churcher, C., Clark, L., Corton, C., Cronin, A. Doggett, J., Dowd, L., Feltwell, T., Hance, Z., Harris, B., Hauser, H., Holroyd, S. Jagels, K., James, K.D., Lennard, N., Line, A., Mayes, R., Moule, S., Mungall, K., Ormond, D., Quail, M.A., Rabbinowitsch, E., Rutherford, K., Sanders, M., Sharp, S. Simmonds, M., Stevens, K., Whitehead, S., Barrell, B.G., Spratt, B.G., Parkhill, J., 2004. Complete genomes of two clinical Staphylococcus aureus strains: evidence for the rapid evolution of virulence and drug resistance. Proc. Natl. Acad. Sci. U. S. A. 101, 9786-9791. http://dx.doi.org/10.1073/pnas.0402521101.

Ito, T., Hiramatsu, K., Oliveira, D.C., De Lencastre, H., Zhang, K., Westh, H., O’Brien, F., Giffard, P.M., Coleman, D., Tenover, F.C., Boyle-Vavra, S., Skov, R.L., Enright, M.C., Kreiswirth, B., Kwan, S.K., Grundmann, H., Laurent, F., Sollid, J.E., Kearns, A.M., Goering, R., John, J.F., Daum, R., Soderquist, B., 2009. Classification of staphylococcal cassette chromosome mec (SCCmec): Guidelines for reporting novel SCCmec elements. Antimicrob. Agents Chemother. 53 (12), 4961-4967. http://dx.doi.org/10. 1128/AAC.00579-09.

Jansen, W.T.M., Beitsma, M.M., Koeman, C.J., van Wamel, W.J.B., Verhoef, J., Fluit, A.C., 2006. Novel mobile variants of Staphylococcal Cassette Chromosome mec in Staphylococcus aureus. Antimicrob. Agents Chemother. 50, 2072-2078. http://dx.doi.
org/10.1128/AAC.01539-05.

Jia, B., Raphenya, A.R., Alcock, B., Waglechner, N., Guo, P., Tsang, K.K., Lago, B.A., Dave, B.M., Pereira, S., Sharma, A.N., Doshi, S., Courtot, M., Lo, R., Williams, L.E., Frye, J.G., Elsayegh, T., Sardar, D., Westman, E.L., Pawlowski, A.C., Johnson, T.A., Brinkman, F.S.L., Wright, G.D., McArthur, A.G., 2017. CARD 2017: expansion and model-centric curation of the comprehensive antibiotic resistance database. Nucleic Acids Res. 45, D566-D573. http://dx.doi.org/10.1093/nar/gkw1004.

Laarhoven, L.M., de Heus, P., van Luijn, J., Duim, B., Wagenaar, J.A., van Duijkeren, E., 2011. Longitudinal study on methicillin-resistant Staphylococcus pseudintermedius in households. PLoS One 6, e27788. http://dx.doi.org/10.1371/journal.pone.0027788.

Li, S., Skov, R.L., Han, X., Larsen, A.R., Larsen, J., Sørum, M., Wulf, M., Voss, A., Hiramatsu, K., Ito, T., 2011. Novel types of Staphylococcal Cassette Chromosome mec elements identified in clonal complex 398 methicillin-resistant Staphylococcus aureus strains. Antimicrob. Agents Chemother. 55, 3046-3050. http://dx.doi.org/10.1128/ AAC.01475-10.

Mateus, A., Brodbelt, D.C., Barber, N., Stärk, K.D.C., 2011. Antimicrobial usage in dogs and cats in first opinion veterinary practices in the UK. J. Small Anim. Pract. 52, 515-521. http://dx.doi.org/10.1111/j.1748-5827.2011.01098.x.

McCarthy, A.J., Harrison, E.M., Stanczak-Mrozek, K., Leggett, B., Waller, A., Holmes, M.A., Lloyd, D.H., Lindsay, J.A., Loeffler, A., 2015. Genomic insights into the rapid emergence and evolution of MDR in Staphylococcus pseudintermedius. J. Antimicrob. Chemother. 70, 997-1007. http://dx.doi.org/10.1093/jac/dku496.

Moodley, A., Stegger, M., Zakour, Ben, Fitzgerald J.R., N.L., Guardabassi, L., 2009. Tandem repeat sequence analysis of staphylococcal protein A (spa) gene in methicillin-resistant Staphylococcus pseudintermedius. Vet. Microbiol. 135, 320-326. http:// dx.doi.org/10.1016/j.vetmic.2008.09.070.

Nucifora, G., Chu, L., Misra, T.K., Silver, S., 1989. Cadmium resistance from Staphylococcus aureus plasmid pI258 cadA gene results from a cadmium-efflux ATPase. Proc. Natl. Acad. Sci. U. S. A. 86, 3544-3548.

Perreten, V., Kadlec, K., Schwarz, S., Andersson, Grönlund, Finn, U., Greko, M., Moodley, C., Kania, A., Frank, S.A., Bemis, L.A., Franco, D.A., Iurescia, A., Battisti, M., Duim, A., Wagenaar, B., van Duijkeren, J.A., Weese, E., Fitzgerald J.R., J.S., Rossano, A., Guardabassi, L., 2010. Clonal spread of methicillin-resistant Staphylococcus pseudintermedius in Europe and North America: an international multicentre study. J. Antimicrob. Chemother. 65, 1145-1154. http://dx.doi.org/10.1093/jac/dkq078.

Perreten, V., Chanchaithong, P., Prapasarakul, N., Rossano, A., Blum, S.E., Elad, D., Schwendener, S., 2013. Novel pseudo-staphylococcal cassette chromosome mec element ( $\psi$ SCCmec57395) in methicillin-resistant Staphylococcus pseudintermedius CC45. Antimicrob. Agents Chemother. 57, 5509-5515. http://dx.doi.org/10.1128/AAC. 00738-13.

Sasaki, T., Kikuchi, K., Tanaka, Y., Takahashi, N., Kamata, S., Hiramatsu, K., 2007. Methicillin-resistant Staphylococcus pseudintermedius in a veterinary teaching hospital. J. Clin. Microbiol. 45, 1118-1125. http://dx.doi.org/10.1128/JCM.02193-06.

Seemann, T., 2014. Prokka: rapid prokaryotic genome annotation. Bioinformatics 30, 2068-2069. http://dx.doi.org/10.1093/bioinformatics/btu153.

Soedarmanto, I., Kanbar, T., Ülbegi-Mohyla, H., Hijazin, M., Alber, J., Lämmler, C., Akineden, Ö., Weiss, R., Moritz, A., Zschöck, M., 2011. Genetic relatedness of methicillin-resistant Staphylococcus pseudintermedius (MRSP) isolated from a dog and the dog owner. Res. Vet. Sci. 91, e25-7. http://dx.doi.org/10.1016/j.rvsc.2011.01. 027.

Solyman, S.M., Black, C.C., Duim, B., Perreten, V., van Duijkeren, E., Wagenaar, J.A., Eberlein, L.C., Sadeghi, L.N., Videla, R., Bemis, D.A., Kania, S.A., 2013. Multilocus sequence typing for characterization of Staphylococcus pseudintermedius. J. Clin. Microbiol. 51, 306-310. http://dx.doi.org/10.1128/JCM.02421-12.

Sullivan, M.J., Petty, N.K., Beatson, S.A., 2011. Easyfig: a genome comparison visualizer. Bioinformatics 27, 1009-1010. http://dx.doi.org/10.1093/bioinformatics/btr039.

Takano, T., Higuchi, W., Otsuka, T., Baranovich, T., Enany, S., Saito, K., Isobe, H., Dohmae, S., Ozaki, K., Takano, M., Iwao, Y., Shibuya, M., Okubo, T., Yabe, S., Shi, D., Reva, I., Teng, L.-J., Yamamoto, T., Yamamoto, T., 2008. Novel characteristics of community-acquired methicillin-resistant Staphylococcus aureus strains belonging to multilocus sequence type 59 in Taiwan. Antimicrob. Agents Chemother. 52, 837-845. http://dx.doi.org/10.1128/AAC.01001-07.

Weese, J.S., van Duijkeren, E., 2010. Methicillin-resistant Staphylococcus aureus and Staphylococcus pseudintermedius in veterinary medicine. Vet. Microbiol. 140, 418-429. http://dx.doi.org/10.1016/j.vetmic.2009.01.039.

Yoon, J.W., Lee, K.-J., Lee, S.-Y., Chae, M.-J., Park, J.-K., Yoo, J.-H., Park, H.-M., 2010. Antibiotic resistance profiles of Staphylococcus pseudintermedius isolates from canine patients in Korea. J. Microbiol. Biotechnol. 20, 1764-1768.

Zankari, E.E., Hasman, H., Cosentino, S., Vestergaard, M., Rasmussen, S., Lund, O., Aarestrup, F.M., Larsen, M.V., 2012. Identification of acquired antimicrobial resistance genes. J. Antimicrob. Chemother. 67, 2640-2644. http://dx.doi.org/10. $1093 / \mathrm{jac} / \mathrm{dks} 261$.

van Duijkeren, E., Catry, B., Greko, C., Moreno, M.A., Pomba, M.C., Pyörälä, S Ruzauskas, M., Sanders, P., Threlfall, E.J., Torren-Edo, J., Törneke, K., 2011. Review on methicillin-resistant Staphylococcus pseudintermedius. J. Antimicrob. Chemother. 66, 2705-2714. http://dx.doi.org/10.1093/jac/dkr367. 